\title{
The Ross inclusion technique
}

\author{
Peter D. Skillington ${ }^{1,2}$, Campbell D. Flynn ${ }^{2,3}$, Marco Larobina ${ }^{1,2}$, Michael O'Keefe ${ }^{1}$ \\ ${ }^{1}$ Department of Cardiothoracic Surgery, Royal Melbourne Hospital, Victoria, Australia; ${ }^{2}$ Epworth Hospital, Richmond, Victoria, Australia; ${ }^{3}$ The \\ Collaborative Research (CORE) Group, Macquarie University, Sydney, Australia \\ Correspondence to: Peter D. Skillington, MB, BS, FRACS. Department of Cardiothoracic Surgery, Royal Melbourne Hospital, PARKVILLE, VIC \\ 3050, Australia. Email: peter.skillington@mh.org.au.
}

Submitted Nov 17, 2020. Accepted for publication May 27, 2021.

doi: $10.21037 /$ acs-2020-rp-15

View this article at: http://dx.doi.org/10.21037/acs-2020-rp-15

\section{Clinical vignette}

A thirty-year old man presented relatively asymptomatic, having had a loud ejection systolic cardiac murmur detected. There were no significant cardiovascular risk factors or medical comorbidities. An echocardiogram revealed severe aortic valve stenosis with mean transvalvular gradient of $45 \mathrm{mmHg}$. There was additional moderate aortic insufficiency. Appearances were of a congenital bicuspid or uni-cuspid aortic valve. A coronary angiogram showed normal origins of the coronary arteries, a dominant right coronary artery, no evidence of coronary disease, and a mildly enlarged ascending aorta.

\section{Surgical technique}

\section{Preparation}

The patient is anesthetised and a Swan-Ganz catheter placed with the tip in the right atrium for advancement to the pulmonary artery at the completion of the operation. The patient is positioned for a median sternotomy and pre-operative broad-spectrum antibiotic coverage is administered.

\section{Exposition}

A median sternotomy is performed and standard cardiopulmonary bypass (CPB) established with a single venous cannula placed via the right atrial appendage, core cooling to $32{ }^{\circ} \mathrm{C}$. The left ventricle $(\mathrm{LV})$ is vented via the right superior pulmonary vein; after aortic cross-clamping, myocardial protection is achieved with intermittent antegrade and retrograde tepid blood cardioplegia.
Prior to commencing bypass, the left anterior pulmonary sinus is marked with a fine Nylon suture, for later orientation of this sinus to the patient's right coronary sinus.

\section{Operation}

A transverse aortotomy incision is made $5-6 \mathrm{~mm}$ above the sinotubular junction, with the aorta transected at this point. The aortic valve is inspected, then excised; the left atrium is cleared off the right side of the aortic root. The diameter of the sinotubular junction (STJ) and aortic annulus is checked with graduated cylindrical or barrel sizers, confirming correlation with the transesophageal echocardiogram (TOE) and pre-operative computed tomography (CT) measurement. A vertical incision is then made from the transverse aortotomy down to the mid-point of the noncoronary sinus, to within $4 \mathrm{~mm}$ of the annulus to provide maximum exposure of the aortic annulus; and in the case of a Siever's Type I bicuspid aortic valve (BAV, with fused $\mathrm{R} / \mathrm{L}$ raphe), a partial circumference external Dacron graft is often placed in this region. Narrowing of the STJ (if enlarged) also takes place via a wedge-shaped excision of non-coronary sinus tissue.

Invariably, in patients with BAV (the predominant valve morphology in younger patients), the aortic annulus (AA) needs to be reduced. The rule of thumb is to reduce the AA to 24-25 $\mathrm{mm}$ for a male patient (depending on size, height, etc.), and 22-24 mm for females. The partial circumference annuloplasty ring is inserted using interrupted horizontal 2.0 braided non-pledgetted sutures, as shown in the video. The Dacron band is taken from a tube graft, which can later be used to replace an enlarged ascending aorta, if required. It is centred on the non-fused sinus (usually the non-coronary) 
and its length depends on how much the AA needs to be narrowed in order to achieve the desired diameter above.

The pulmonary autograft is excised in a standard fashion, and the thawed pulmonary allograft is sutured into position to restore right ventricular outflow tract continuity.

Equidistant points are marked around the AA to guide suture placement for the autograft insertion. Holes are crated in the autograft sinuses for later anastomosis of right coronary artery (RCA), and left coronary artery (LCA) ostia. The trimmed and prepared autograft is sutured into position at the level of the AA, using multiple interrupted 4-0 Prolene sutures. The left and right coronary ostia are then excised as buttons, brought inside the aortic root, and anastomosed to the previously created fenestrations in the autograft sinuses, using 6-0 Prolene. In the case of the LCA, slightly more aortic sinus tissue is excised on both the right and left side to facilitate this anastomosis and to minimise the risk of kinking of the LCA, when the aortic root is pressurized and the ostial anastomosis is not as easily visualised.

The vertical incision in the non-coronary sinus, is now closed with 5-0 Prolene, fully encompassing the autograft within the aortic root. If a triangular excision of noncoronary sinus tissue took place, this also narrows the aortic root and STJ, so that it can better prevent late aortic regurgitation, caused by dilatation of the distal autograft. The autograft is trimmed in height, such that it is the same height as the patient's aortic root.

The distal anastomosis of the autograft to the patient's distal ascending aorta is performed using 4-0 Prolene. In the region cephalad to the LCA ostial anastomosis, this suture line also includes the distal aortic root. The longitudinal line (made by a surgical felt tip marking pen) together with the left non-coronary commissure, guides the alignment of this anastomosis. If the ascending aorta is replaced with a Dacron graft, both the aortic root and pulmonary autograft are trimmed further in height (the autograft to just above the commissural tips), and the autograft commissures lined up at equidistant points marked on the graft.

\section{Completion}

After release of the aortic cross-clamp, the two coronary anastomoses are inspected to ensure they are visible and that there is unimpeded exit of the coronary arteries from the aortic root. The lower aortic remnant is tacked up anteriorly to the distal autograft anastomosis with interrupted figure-of-eight Nylon sutures, to ensure that it cannot slip down and obstruct the right coronary artery. Once the heart is beating nicely, there is removal of the $\mathrm{LV}$ vent, placement of atrial and ventricular pacing wires, and finally, weaning from CPB. TEE examination of aortic valve and $L V$ function is performed, to ensure no wall motion abnormalities, as well as advancement of the SwanGanz catheter to the pulmonary artery. Hemostasis is achieved, with pericardial and sternotomy closure, leaving a mediastinal chest drain, and posterior pericardial suction drains in situ.

\section{Comments}

Using this technique $(1,2)$, we now have experience with 600 cases, with 500 of these performed by the senior author over a twenty-eight-year period. There has been one early mortality (EM $0.2 \%$ ), while freedom from reoperation on the aortic valve is $96 \%$ at twenty years, and $99 \%$ when performed for pure aortic stenosis (3). Freedom from reoperation on the pulmonary valve is $97 \%$ at twenty years (4).

This root-within-root technique for inserting the autograft gives autologous support to the autograft, thus minimizing any prosthetic material, and preventing late aortic root dilatation. Serial echocardiograms have shown that the aortic root does not expand significantly after this procedure (2).

The technique described is perhaps more complicated to perform than a standard unsupported root replacement, and care needs to be taken to ensure that the coronary arteries are not kinked or obstructed as they exit the aortic root, particularly the LCA.

\section{Acknowledgments}

Funding: None.

\section{Footnote}

Conflicts of Interest: The authors have no conflicts of interest to declare.

Open Access Statement: This is an Open Access article distributed in accordance with the Creative Commons Attribution-NonCommercial-NoDerivs 4.0 International License (CC BY-NC-ND 4.0), which permits the noncommercial replication and distribution of the article with the strict proviso that no changes or edits are made and the 
original work is properly cited (including links to both the formal publication through the relevant DOI and the license). See: https://creativecommons.org/licenses/by-nc-nd/4.0/.

\section{References}

1. Skillington PD, Mokhles MM, Takkenberg JJ, et al. Twenty-year analysis of autologous support of the pulmonary autograft in the Ross procedure. Ann Thorac Surg 2013;96:823-9.

2. Skillington PD, Mokhles MM, Takkenberg JJ, et al. The

Cite this article as: Skillington PD, Flynn CD, Larobina M, O'Keefe M. The Ross inclusion technique. Ann Cardiothorac Surg 2021;10(4):541-543. doi: 10.21037/acs-2020-rp-15
Ross procedure using autologous support of the pulmonary autograft: techniques and late results. J Thorac Cardiovasc Surg 2015;149:S46-S52.

3. Skillington PD, Mokhles MM, Wilson W, et al. Inclusion cylinder method for aortic valve replacement utilising the Ross operation in adults with predominant aortic stenosis - 99\% freedom from re-operation on the aortic valve at 15 years. Glob Cardiol Sci Pract 2013;2013:383-94.

4. Fricke TA, Skillington PD, Shi WY, et al. Pulmonary Valve Function Late After Ross Procedure in 443 Adult Patients. Ann Thorac Surg 2020;109:1127-31. 